\title{
A AUSÊNCIA DO DIÁLOGO NO PROCESSO DE FORMAÇÃO PROFISSIONAL EM SAÚDE NO ENSINO REMOTO: IMPACTOS NA APRENDIZAGEM E NA SAÚDE MENTAL DE ACADÊMICOS
}

\author{
LA AUSENCIA DE DIALOGO EN EL PROCESO DE ENTRENAMIENTO DE SALUD \\ PROFESIONAL EN EDUCACION REMOTA: IMPACTOS EN EL APRENDIZAJE Y LA \\ SALUD MENTAL DE LOS ACADÉMICOS
}

\author{
THE ABSENCE OF DIALOGUE IN THE PROCESS OF PROFESSIONAL \\ FORMATION IN HEALTH IN REMOTE EDUCATION: IMPACTS ON THE \\ LEARNING AND MENTAL HEALTH OF ACADEMICS
}

\author{
Mesaque Silva CORREIA ${ }^{1}$ \\ Neuton Alves ARAÚJO ${ }^{2}$ \\ Bruna Gabriela MARQUES ${ }^{3}$
}

RESUMO: Neste texto o objetivo é o de analisar as significações que alunos vêm produzindo sobre o processo de formação profissional em saúde no ensino remoto. Com o intuito de alcançar o objetivo proposto, nos apropriamos dos pressupostos teóricos e metodológicos da Pedagogia Freireana especialmente dos pressupostos da categoria diálogo. A questão que orientou esta pesquisa foi: Nos discursos dos alunos e professores dos cursos de graduação da área da saúde de uma universidade pública do Piauí, quais as suas possíveis significações (sentidos e significados) produzidas sobre o processo de formação profissional no ensino remoto? Participaram do estudo 10 (dez) acadêmicos, sendo 5 (cinco) do curso de licenciatura em Educação Física e 05 do curso de bacharelado em Psicologia. Especificamente sobre a produção dos dados, se empregou a entrevista semiestruturada que foi realizada no período de 5 a 7 de outubro de 2020. Os resultados da pesquisa evidenciam que o ensino centrado no docente, ancorado na dinâmica da escuta, na impossibilidade de dizer a palavra, de interação e troca de experiências dificulta o processo de produção de conhecimentos. Além disso, os sentidos produzidos a partir dos discursos dos acadêmicos investigados evidenciam que a ausência do diálogo, além de impossibilitar o pronunciamento do mundo através da palavra, institui a cultura do fingir ensinar e do fingir aprender. Para eles, essa situação provoca dor e sofrimento, por se sentirem culpados com relação ao processo de ensino. O que por sua vez, acaba impactando na saúde mental. Consideramos que os sentidos produzidos pelos alunos, dos cursos de Educação Física e Psicologia ao processo de formação profissional em saúde no ensino remoto, os levaram à tomada de consciência quanto ausência do diálogo que dificulta a aprendizagem e impacta na saúde mental.

\footnotetext{
${ }^{1}$ Universidade Federal do Piaú (UFPI), Teresina - PI - Brasil. Professor no Departamento de Métodos e Técnicas de Ensino (DMTE). Doutorado em Educação Física (USJT). ORCID: https://orcid.org/0000-00020258-7111. E-mail: mesaquesilvacorreia@ufpi.edu.br

${ }^{2}$ Universidade Federal do Piauí (UFPI), Teresina - PI - Brasil. Professor Adjunto no Departamento de Métodos e Técnicas de Ensino. Doutorado em Educação (USP). ORCID: https://orcid.org/0000-0003-4320-9536. E-mail: araujo06046@gmail.com

${ }^{3}$ Universidade São Judas Tadeu (USJT), São Paulo - SP - Brasil. Professora nos Cursos de Graduação e de Mestrado em Educação Física. Doutorado em Educação Física (USJT). ORCID: https://orcid.org/0000-00016792-1523. E-mail: bruna.marques@saojuds.br
} 
PALAVRAS-CHAVE: Formação profissional. Ensino remoto. Diálogo. Aprendizagem. Saúde mental.

RESUMEN: En este texto el objetivo es analizar los significados que vienen produciendo los estudiantes sobre el proceso de educación profesional en salud en la educación a distancia. Para lograr el objetivo propuesto, nos apropiamos de los supuestos teóricos y metodológicos de la Pedagogía freireana, especialmente los supuestos de la categoría diálogo. La pregunta que orientó esta investigación fue: En los discursos de estudiantes y profesores de carreras de grado en el área de salud de una universidad pública de Piauí, ¿cuáles son sus posibles significados (sentidos y significados) producidos sobre el proceso de formación profesional en educación remota? En el estudio participaron diez (10) académicos, 5 (cinco) de la carrera de Educación Física y 05 de la Licenciatura en Psicología. Específicamente sobre la producción de los datos, se utilizó la entrevista semiestructurada, que tuvo lugar del 5 al 7 de octubre de 2020. Los resultados de la investigación muestran que la enseñanza se centró en el docente, anclado en la dinámica de la escucha, en la imposibilidad de decir la palabra. , la interacción y el intercambio de experiencias dificultan el proceso de producción de conocimiento. Además, los significados producidos a partir de los discursos de los académicos investigados, muestran que la ausencia de diálogo, además de imposibilitar la pronunciación del mundo a través de las palabras, instituye la cultura de pretender enseñar y pretender aprender. Para ellos, esta situación les causa dolor y sufrimiento, ya que se sienten culpables por el proceso de enseñanza. Lo que a su vez termina afectando la salud mental. Creemos que los significados producidos por los estudiantes, desde los cursos de Educación Física y Psicología hasta el proceso de formación profesional en salud en educación a distancia, los llevaron a tomar conciencia de la ausencia de diálogo que dificulta el aprendizaje e impacta la salud mental.

PALABRAS CLAVE: Formación profesional. Enseñanza remota. Diálogo. Aprendizaje. Salud mental.

ABSTRACT: In this text the objective is to analyze the meanings that students have been producing about the process of professional health education in remote education. To achieve the proposed objective, we appropriate the theoretical and methodological assumptions of Freirean Pedagogy, especially the assumptions of the dialogue category. The question that guided this research was: In the speeches of students and professors of undergraduate courses in the health area of a public university in Piaui, what are their possible meanings (senses and meanings) produced about the professional formation process in remote education? Ten (10) academics participated in the study, 5 (five) of the Physical Education degree course and 05 of the Bachelor's degree in Psychology. Specifically, on the production of data, the semi-structured interview was used, which took place from October 5 to 7, 2020. The research results show that teaching centered on the teacher, anchored in the dynamics of listening, in the impossibility of saying the word, interaction and exchange of experiences hampers the knowledge production process. In addition, the meanings produced from the speeches of the academics investigated, show that the absence of dialogue, in addition to making it impossible to pronounce the world through words, institutes the culture of pretending to teach and pretending to learn. For them, this situation causes pain and suffering, as they feel guilty about the teaching process. Which in turn ends up impacting mental health. We believe that the meanings produced by students, from Physical Education and Psychology courses to the process of professional formation in health in remote 
education, led them to become aware of the absence of dialogue that hinders learning and impacts mental health.

KEYWORDS: Professional qualification. Remote teaching. Dialogue. Learning. Mental health.

\section{Introdução}

Neste texto são apresentados e discutidos resultados de um estudo, amparado nos pressupostos da Pedagogia Freireana, que se propôs a analisar as significações que alunos vêm produzindo sobre o processo de formação profissional em saúde no ensino remoto. É parte de uma pesquisa mais ampla, que foi realizada na região nordeste do Brasil, na cidade de Teresina no Estado do Piauí, envolvendo alunos e professores de dois cursos da área da saúde de uma universidade pública.

Nos ideais educativos de Paulo Freire educar, pois, é assumir uma posição gnoseológica, posição do educando com o educador e vice-versa, para criar, recriar a nova realidade dos homens e das mulheres num processo permanente de libertação. Daí que o ato educativo se torna dialógico e a ação do educando e do educador se faz, também dialógica. Nessa perspectiva, o diálogo se torna um elemento potencializador do pensar crítico/problematizador em relação à condição humana no mundo. Através do diálogo os sujeitos são capazes de dizer o mundo segundos suas visões e compreensões. Além disso, nas esteiras da proposta de uma educação humanista-libertadora, Freire (1996) compreende que o diálogo implica uma práxis social, que se materializa na coerente entre a palavra dita e a ação humanizadora. Para ele,

[...] a ação e reflexão, de tal forma solidárias, em uma interação tão radical que, sacrificada, ainda que em parte, uma delas, se ressente, imediatamente, a outra. Não há palavra verdadeira que não seja práxis. Daí que dizer a palavra verdadeira seja transformar o mundo (FREIRE, 1992, p. 77).

A partir dessa compreensão, quando a educação deixa de primar pelo diálogo o processo educativo deixa de produzir conhecimento, já que a produção de conhecimento só existe na criação e na transformação. O que passa a existir é uma apropriação do conteúdo pelo educador que, no decorrer do processo educativo, doa-os aos seus educandos, gerando a absolutização da ignorância, isto é, conceber-se como o dono do conhecimento e seus alunos e alunas como aqueles que nada sabem (FREIRE, 1997). 
Contrariando a perspectiva freireana de educação, a qual, concebe a ação educativa como uma ação dialógica e por extensão humanizadora. Ação em que o diálogo assume uma função essencial no processo de construção do conhecimento. Compreende Freire que é na relação dialógica entre os sujeitos e o objeto cognoscível que a produção do conhecimento acontece. Para o autor, o conhecimento é uma construção coletiva, mediada pelo diálogo, que deve articular dialeticamente a experiência da vida cotidiana com a sistematização rigorosa e crítica (FREIRE, 1971).

Desse modo, a ausência do diálogo, pressupõe a ausência da conscientização, e por extensão da humanização. O diálogo é a via pela qual os sujeitos pronunciam a palavra verdadeira, palavra que adquire a responsabilidade de dizer o mundo e fazer o mundo, pois é por meio dela que a práxis educativa, enquanto social e política se compromete com a humanização de homens e mulheres. Pois, no entendimento de Freire (1976), somente o pensar verdadeiro é capaz de levar os sujeitos a construir sua própria história como ser histórico, levando-os a reconhecer e transformar criticamente os condicionamentos que estão inseridos na realidade. Assim o diálogo se constitui como um caminho, no qual os sujeitos estão em permanente movimento de construção e reconstrução.

Dito isso, é possível asseverar que, a vocação da pedagogia freireana nasceu, cresceu e se afirmou com o compromisso gnosiológico, com o desenvolvimento de uma educação libertadora na qual o diálogo é explicitamente assumido como finalidade, que objetiva pensar os seres humanos como seres em relação com o mundo. Por essa razão, a epistemologia freireana, enfatiza que se não há diálogo não há aprendizado e muito menos humanização. Já que a ausência do diálogo impossibilita o encontro entre sujeitos, e dos sujeitos com o mundo ao pronunciá-lo. Impedindo a construção de um pensar verdadeiro que seja capaz de transformar a realidade circundante (FREIRE, 1979).

Tendo em vista o exposto, é possível sustentar que com o aparecimento da COVID-19 - uma doença desconhecida que afeta a capacidade respiratória e progride rapidamente para casos de internação e óbito que apareceu no fim do ano de 2019, na província chinesa de Wuhan e se espalhou rapidamente pelo mundo, fazendo com que a Organização Mundial da Saúde (OMS) caracterizasse a situação como pandemia (FREITAS; NAPIMOGA; DONALISIO, 2020; BARBOSA BATISTA; VIEIRA FERNANDES, 2020). Educadores de todo o mundo foram desafiados a serem inventores e reinventores dos meios que possibilitem a problematização do objeto, ou da realidade a ser descoberta e apreendida pelos sujeitos do 
processo educativo por meio do "ensino remoto emergencial ${ }^{4}$ realizado através de diversas plataformas digitais.

Isto porque, o distanciamento social, tornou-se uma das estratégias principais para evitar a propagação do vírus e a sobrecarga do sistema de saúde. Com isso, no início da disseminação viral, os governos determinaram sobre a suspensão de aulas presenciais em todas as esferas da educação. Gerando novas demandas ao ensino. Levando as instituições educativas a buscarem métodos, técnicas, estratégias e tecnologias inovadoras de ensino ao desenvolvimento das aulas (FERREIRA et al., 2020).

Todavia, a reconfiguração da sala de aula, e o uso de novas estratégias pedagógicas trouxe preocupação aos gestores das instituições de ensino e educadores, a exemplo da: capacitação docente, a garantia de acesso por parte dos estudantes, adaptação dos estudantes, impacto na saúde mental da comunidade e organização do tempo para estudo.

Infelizmente, a decisão de oferta do ensino remoto, nem sempre aconteceu mediada pela escuta acurada dos agentes educativos (gestores educacionais, educadores e alunos). $\mathrm{Na}$ maioria dos casos a decisão foi tomada de forma horizontal e desconectada da realidade cultural, social e econômica de alunos e professores, gerando problemas de exclusão social, de aprendizagem e saúde mental.

Desse modo, a questão que orientou esta pesquisa foi: nos discursos dos alunos e professores dos cursos de graduação da área da saúde de uma universidade pública do Piaú, quais as suas possíveis significações (sentidos e significados) produzidas sobre o processo de formação profissional no ensino remoto?

Assim, o objetivo deste estudo é de analisar as significações que alunos e professores vêm produzindo sobre o processo de formação profissional em saúde no ensino remoto.

\section{Procedimentos metodológicos}

Por considerarmos o problema, o objetivo e, sobretudo, o referencial teóricometodológico que assumimos neste estudo, trabalhamos com a pesquisa explicativa por corroborar das ideias de Vigotski (2007), ao postular que devemos explicar e não nos limitarmos às descrições nominais do processo que compõe o fenômeno investigado, que no caso deste estudo são as significações que alunos e professores vêm produzindo sobre o

${ }^{4}$ Considerada uma solução temporária e estratégica que permitirá, no contexto da Pandemia de Covid-19 proporcionar os sistemas de ensino (privado, estaduais, municipais e federais) a possibilidade de manter, dentro das circunstâncias possíveis, as atividades de ensino. 
processo de formação profissional em saúde no ensino remoto. Tal pressuposto foi cunhado de "explicação versus descrição" (VIGOTSKI, 2007).

Nas condições postas, entendemos que o referido tipo de pesquisa substancia a produção de respostas sobre as significações que alunos e professores vêm produzindo sobre o processo de formação profissional em saúde no ensino remoto.

Esclarecemos, ainda, que os 10 (dez) alunos participantes, sendo 5 (cinco) do curso de licenciatura em Educação Física e 05 do curso de bacharelado, escolhidos aleatoriamente. Os quais concordaram em assinar o Termo de Consentimento Livre e Esclarecido (TCLE), autorizando a participação nas atividades deste estudo. A fim da garantia do anonimato dos acadêmicos investigados neste estudo, empregamos números.

Especificamente sobre a produção dos dados, utilizamos a entrevista semiestruturada. Para Aguiar e Ozella (2006), se trata de uma técnica rica para a construção de dados em pesquisa por permitir o acesso aos processos psíquicos da produção das significações. $O$ roteiro de entrevista abordou as seguintes questões: Quais as significações do ensino remoto para você? De que forma as aulas remotas são realizadas? De que forma são produzidos os conhecimentos no decorrer das aulas? Quais os impactos do ensino remoto na sua formação profissional e na sua vida?

Os dados produzidos em decorrência das entrevistas foram submetidos à proposta de Gaskins, Miller e Corsaro (1992). Estes autores indicam o uso da abordagem interpretativa quando o foco da investigação são as significações da ação humana frente a contextos culturais específicos. As entrevistas foram realizadas via e-mail no período de 05 a 07 de outubro de 2020. Foram transcritas na íntegra e foi realizada uma análise-síntese dos dados com o intuito de obtenção das principais mensagens-chave. Em seguida, foram extraídos os fragmentos dos discursos relevantes à compreensão do objetivo e problema da investigação.

Assim, para proceder com a sessão das análises (resultados e discussões), organizamos os dados em 2 (duas) categorias: 1) Significações inicialmente produzidas sobre o processo de formação profissional em saúde no ensino remoto. 2) Movimento de produção de novos sentidos sobre os impactos do ensino remoto na sua formação profissional e na sua vida do docente. 


\section{Resultados e discussões}

Nesta seção, com o propósito de analisarmos as significações que acadêmicos vêm produzindo sobre o processo de formação profissional em saúde no ensino remoto, procuramos nos aproximar das experiências vivenciadas pelos acadêmicos, sujeitos deste estudo, no decorrer de formação profissional no ensino remoto. Dessa forma, para facilitar a análise dos dados produzidos por meio da entrevista semiestruturada, trabalhamos com as categorias: Significações inicialmente produzidas sobre o processo de formação profissional em saúde no ensino remoto. Movimento de produção de novos sentidos sobre os impactos do ensino remoto na sua formação profissional e na sua vida

\section{Significações inicialmente produzidas sobre o processo de formação profissional em saúde no ensino remoto}

As significações, inicialmente, manifestadas pelos alunos, sujeitos desta pesquisa, sobre o processo de formação profissional em saúde no ensino remoto, emergem de suas vivências nas aulas remotas realizadas no primeiro semestre de 2020 , e trazem à tona a ausência do diálogo no decorrer do processo formativo, como é o caso dos alunos $-01,02$, 03, ao nos revelarem que:

Iniciei o periodo especial muito empolgada com as aulas, afinal, desde que entrei na universidade o discurso pedagógico era que vivemos em uma sociedade tecnológica, informatizada e da informação. E que nós, futuros professores necessitaríamos nos alfabetizarmos tecnologicamente para acompanharmos o desenvolvimento desta sociedade que caminha a passos largos. Iniciei as aulas, na expectativa de aprender com meus professores estratégias, métodos e técnicas para desenvolver minha ação profissional neste novo mundo. Frustrante! Com o desenvolvimento das aulas observei que nossa sociedade é tecnológica, mas a maioria da população não tem acesso às mídias digitais e os que possuem acesso não dominam tais tecnologias. Nossas aulas são frias, sem interação, sem diálogo, sem troca, sem questionamento. Aqueles professores que me cobravam a inserção com o mundo tecnológico descobriram que eles próprios estão apartados dessa sociedade. Não são aulas são monólogos, eu não falo, eu digito e se der sorte a professora realiza a leitura do chat e responde quando tiver um tempo (Entrevista).

Nossas aulas deixam a desejar, não por culpa dos professores, porque assim como nós muitos têm problemas de conexão e até de manuseio das mídias digitais. É dificil falar durante as aulas, se você conseguir ser percebido já tá com sorte. Quase sempre saio frustrado, cansado, e com a sensação que eu poderia ter feito algo para melhorar, para ajuda no desenvolvimento do diálogo. Acho que desde o início da pandemia, aula mesmo nunca mais teve (Entrevista). 
As aulas virtuais têm uma dinâmica muito peculiar, os professores quase sempre centralizam a fala e utilizam como recurso suas projeções. Os alunos quase sempre com as câmeras dos celulares e computadores desligados ficam na posição de escuta. Uma vez ou outra, os professores lembram que estão com os alunos e buscam saber se a turma está escutando e entendendo. A resposta dos alunos é sempre a mesma: Sim! No fundo as aulas remotas realizadas no plano da centralização da fala, são só falas e pouca aula, pouca troca, pouco aprendizado. Mais muita cobrança com as atividades assíncronas (Entrevista).

Nessa mesma linha argumentativa, podemos destacar o discurso dos alunos $-04,05$ 06 e 07:

As aulas são boas, poderiam ser melhores se os professores encontrassem uma forma de fazer com que os alunos participassem mais. Eu saio da aula zonzo com tanta informação. Na maioria das vezes não tenho espaço para perguntar, tirar dúvidas e até mesmo compartilhar conhecimentos $e$ experiências (Entrevista).

Nossas aulas são sempre tensas, porque nós entramos na aula e não sabemos até que horas vamos permanecer ali. Tem professor que é sensivel ao problema, outros acham que é desculpa dos alunos. É não, tem muita gente que foi para o interior e não tem acesso a uma internet boa, outros usam dos vizinhos, parentes e colegas. Outro ponto que prejudica é a forma com as aulas acontecem, os professores ministram os conteúdos e os alunos ficam nos bastidores escutando e tentando entender. É uma aula que pouco aprendemos e ficamos mesmo é na torcida para permanecermos na sala até o fim da aula, momento em que somos obrigados a abrirmos as câmeras $e$ pronunciar a palavra: PRESENTE. Talvez esta seja um dos raros momentos que falamos nas aulas (Entrevista).

Sofro muito durante as aulas. Kkkkk. Eu fico no chat pedindo a fala e nada, quando me dão o que eu ia dizer já não faz mais sentido (Entrevista).

As aulas acontecem sempre no meeting, os professores enviam o link pelo sistema ou pelo grupo do whatsApp, mas às vezes o acesso não dá certo, ai tem que agendar a aula na hora. Kkkk. As aulas são sempre centradas nos professores, alguns usam projeção, outros nem isso sabem usar e fica tudo na fala mesmo. Não tem conversa entre professor e aluno, nós usamos mesmo é o chat para nos comunicarmos, a comunicação no chat é mais entre os alunos, têm aula que o professor nem consulta o chat. Não gosto das aulas, é muito conteúdo e pouco aprendizado (Entrevista).

A respeito dos discursos dos alunos em tela, podemos observar a denúncia com relação a ausência do diálogo no desenvolvimento das aulas. O que segundo os alunos acarreta prejuízos a construção do conhecimento. Nas esteiras do pensamento freireano, não se pode fazer educação de uma pessoa à outra, mas sim de uma pessoa com a outra, intermediados pelo mundo. Dessa forma, ele critica processos educativos verticalizados, centralizados na figura do professor detentor do conhecimento e depositador de saberes 
(FREIRE, 1980). Em sua ideologia, o diálogo deve fazer parte do processo educativo desde o momento do planejamento, na escolha do conteúdo programático a ser trabalhado pelo educador-educando. Em sua compreensão, esse conteúdo não deve ser uma doação do sábio ou do líder revolucionário aos incultos, mas "a devolução organizada, sistematizada e acrescentada ao povo daqueles elementos que este lhe entregou de forma desestruturada" (FREIRE, 1996, p. 23).

Diante disso, o diálogo torna-se uma ferramenta para que os alunos tenham compreensão não apenas teórica e abstrata dos conteúdos apresentados e das realidades problematizadas, mas dos vários níveis de significações que possam ter dela. Dessa maneira, o conteúdo programático deve refletir as contradições da situação existencial concreta dos alunos, através do diálogo, entre as significações que dele o tenham, o educador e os educandos em busca de respostas que se processem no plano das ideais e principalmente no mundo material (FREIRE, 1997).

Por esse motivo, o diálogo, não pode ser compreendido como a ação de uma pessoa, ou de uma a outra, tem que se constituir na relação das pessoas ao pronunciar o mundo. Por isso, não pode haver diálogo entre os que querem a transformação do mundo e os que elaboram a propaganda dos que não a desejam, pois, estes sempre vão tentar impedir aqueles de "dizer o mundo" (FREIRE, 1992, p. 91).

Podemos afirmar ainda, a partir da análise dos discursos apresentados pelos alunos 08 e 09, que as significações produzidas por eles, inicialmente, acerca do processo de formação profissional em saúde no ensino remoto, evidenciam a existência da cultura do fingir ensinar e do fingir aprender. Cultura alimentada pela dificuldade de estabelecimento de relações dialógicas, em virtude da inexistência de estratégias de ensino que possibilitem os alunos dizerem a palavra e pronunciarem o mundo.

Eu saio das aulas sempre frustrada. Na verdade, nem sei se podemos caracterizar os encontros virtuais como aulas. Desde que iniciaram, não houve um único encontro em que um professor ou um aluno não teve problemas para permanecer na aula. Parece que nada flui, não há diálogo, não há interação, não há troca. Não é aula! É um faz de conta! Estamos cumprindo tabela (Entrevista).

Na real, já pensei em desistir, são muitos trabalhos sem sentido, muitas falas soltas e sem questionamentos, muitas entradas e saidas das aulas por conta da conexão. Na verdade, poucas coisas deu para compreender até agora, e tenho dúvidas se ainda aprenderei alguma coisa. Tenho consciência que o que estou deixando de aprender me fará muita falta. O fato é que não tem ensino e não tem aprendizado, temos consciência deste fato, apenas, mas 
continuamos acompanhando as aulas para não perdermos mais tempo (Entrevista).

Com a intencionalidade de reforçar essa constatação, destacamos, ainda, a fala do aluno -10

Um curso com as características do nosso, o diálogo é fundamental para que possamos interagir e aprender. Nas aulas remotas é o que eu mais sinto falta, é o que me pega. Quando falamos, os professores logo interrompem por conta do tempo, a justificativa é sempre a mesma: agora a dinâmica da aula é outra. Ai me questiono: será que dinâmica da escuta é suficiente para o desenvolvimento da aprendizagem? Eu quero ouvir, mas também quero ser ouvida. Minha dinâmica é da troca. Não quero pra mim a dinâmica do dizer que aprendeu e tá visivel que não se compreendeu nada, mais tudo tem, lá fora se aprende (Entrevista).

Todas essas significações produzidas pelos alunos 08 e 09 e 10, inicialmente manifestadas sobre processo de formação profissional em saúde no ensino remoto, convergem às ponderações de Correia, Miranda e Velardi (2011), ao afirmarem que a educação deve ser pensada para libertar e emancipar o conhecimento e o indivíduo, a fim de que ele empodere a sua realidade, não podemos compactuar com o desenvolvimento de uma educação inculcadora, alienadora, repressora e fingidora de libertação.

Uma sociedade democrática só se constrói com responsabilidade. Uma educação voltada para a conscientização, para humanização é uma imposição desta mesma sociedade. É contraditório o discurso do desenvolvimento de um ensino alicerçado apenas na dinâmica da escuta por parte dos alunos. Pois o não direito ao dizer a palavra, contribui com o desenvolvimento de um ensino centrado no professor, ausente de diálogo, fingidor e adestrador (WERNECK, 1992). Como diz Freire (1980), nas relações sociais a palavra assume o sentido de dizer o mundo e fazer o mundo. A palavra verdadeira é práxis social comprometida com o processo de humanização, em que ação e reflexão estão dialeticamente constituídas. Portanto, qualquer ação contrária, é ação solitária e sem sentido. O que de certa forma justifica as significações dos alunos com relação à cultura do fingir ensinar e fingir aprender presente no processo de formação profissional em saúde no ensino remoto.

\section{Movimento de produção de novos sentidos sobre os impactos do ensino remoto na sua formação profissional e na vida}

Para a análise dos dados produzidos nesta categoria, partimos do pressuposto de que o desenvolvimento da formação profissional em saúde no ensino remoto acentua a tradicional dicotomia entre teoria/prática, sendo dinamizada por meio de aulas expositivas e pouco 
dialógicas, e consequentemente, trazendo prejuízos para o aprendizado e saúde mental dos alunos. No contexto da formação profissional, é importante que o educador assuma o processo educativo como um ato criador, crítico e o diálogo como elemento facilitador do conhecimento. É vital que no decorrer de sua práxis pedagógica sua ação dialética se transforme em testemunho prático de suas convicções político-filosóficas, e que sua práxis pedagógica possa conspirar contra o saber estático, contra a dominação do pensar, contra a reprodução dos gestos padronizados e se oriente por uma "concepção" que almeje a formação de profissionais comprometidos com o desenvolvimento de uma ação profissional galgada no diálogo, na realidade vivida e na emancipação dos sujeitos (FREIRE, 1997). Eis aqui a necessidade da produção de novas significações que, no caso desta subseção analítica, são os sentidos

Face o exposto, o sentido é uma relação e, desse modo, não se ensina. Porém, pode sofrer alterações. Para Leontiev (1983, p. 234, tradução nossa), se trata de uma significação “[...] desenvolvida, claramente conscientizada, dotando o educando de conhecimentos e atitudes correspondentes".

Nos discursos dos alunos selecionados na subseção, apresentaremos indicativos da produção do sentido pessoal que os alunos, sujeitos deste estudo, desenvolveram nas vivências oferecidas no decorrer das aulas remotas na perspectiva defendida por Leontiev (1983).

A realização das nossas aulas ainda provoca muita discussão entre nós. Muitos conteúdos trabalhados pelos professores não são compreendidos por nós. Tudo fica no plano teórico, na abstração, o que acaba prejudicando nosso aprendizado. Às vezes me sinto sozinha nesse processo, parece que o professor não tá ali para nos orientar, nos apoiar, porque no fundo eles precisam mais de orientação e apoio do que nós. Fico entristecida tanto pelo que deixo de aprender como pelo sofrimento dos professores durante as aulas (Entrevista).

Eu sempre me questiono como podemos aprender no decorrer das aulas remotas se estamos sempre no plano da escuta? Se nossas vivências não são levadas em consideração pela ausência do diálogo? Como podemos construir novos conhecimentos, se as aulas não dão condições para estabelecimentos de processos educativos dialógicos? Eu sofro demais com essa situação! Quando eu entrei no curso de Psicologia não imaginei que as aulas seriam desenvolvidas desta forma. Entendo o contexto do ensino emergencial, o que não entendo é esse faz de conta tanto dos professores como dos alunos. Não há ensino! Não há aprendizado! O que há é angústia, sofrimento e culpabilização pelas inúmeras coisas que não dão certo, que não acontecem (Entrevista). 
As aulas remotas pouco acrescentaram na minha formação. Estou fazendo mesmo para concluir o curso. Acho que tudo é muito novo para todos nós, $e$ as condições que professores e alunos possuem para estarem e realizarem as aulas são mínimas e por tanto, precárias. Aprendo muito pouco pela falta de interação durante as aulas. E temos tantas coisas para fazer nos momentos assíncronos que perdemos nossas horas de lazer e nossa liberdade. É um sofrimento! (Entrevista).

Em linhas gerais, estes alunos apresentam uma nova significação, ou seja, um sentido pessoal a respeito do ensino remoto, na formação profissional e em suas vidas, o qual pode ser sintetizado da seguinte forma: "Deixo de aprender" e "Sofrimento". Isso reflete a precariedade com que o ensino remoto vem sendo oferecido, causando prejuízos à formação e adoecimento mental em alunos, o que ainda pode ser constatado nos depoimentos:

Vou levar das aulas muito pouco. As aulas são sempre do mesmo jeito. Não tem vivência, não tem aprendizado. Saio das aulas acabado mentalmente (Entrevista).

Acredito que de tudo temos que tirar proveito, seja positivo ou negativo. Das aulas remotos poucas coisas positivas levarei para minha vida profissional. Agora de certo que aquilo que eu tenho vivido negativamente com meus colegas tentarei mudar na minha prática profissional, como socialização da fala, criação de estratégias de ensino, associação entre ensino e mercado de trabalho. A ausência dessas coisas no decorrer das aulas prejudica nosso aprendizado e provoca sofrimento (Entrevista).

As aulas me frustram, porque na moral não aprendo quase nada. Fico preocupado porque o mercado de trabalho vai nos cobrar e não vai querer saber do nosso atual contexto de aprendizagem. Veja só: aulas que necessitam de interação corporal sendo realizadas via tela de computador e celular em que a escuta a nós é reservada. Não tem teoria/prática, o que tem é teoria desvinculada da prática e do nosso dia a dia porque não podemos fazer essa ponte por conta da ausência do diálogo no decorrer das aulas. Fico preocupado e pensativo quanto a essas coisas (Entrevista).

Tais discursos demonstram que o mencionado ensino é oferecido sem a mínima estrutura básica exigida. As falas dos estudantes nos dão indícios de que a seus professores não foi oferecido nem um tipo de treinamento com foco no desenvolvimento do ensino remoto, fazendo com que eles apresentem dificuldades ao lidar com tecnologias digitais, provocando prejuízos à aprendizagem e sofrimento aos alunos.

Como bem pontua Silva (2020), o medo da doença e o possível não aproveitamento do conteúdo pedagógico tem influenciado negativamente na saúde mental dos alunos. O autor enfatiza que, após, a transferência das aulas presenciais para as aulas remotas, o que tem se observado é alunos tentando compensar as dificuldades de aprendizagem no decorrer das 
aulas. No entanto, essa busca quando exaustiva provoca insegurança, culpabilização e sofrimento mental nos alunos (PITANGA; BECK; PITANGA, 2020).

É o sentido pessoal que foi desenvolvido pelas alunas 07, 08, 09 e 10, respectivamente, como explícito em suas falas:

As aulas remotas me ajudam a concluir o curso, mas aprendo muito pouco com elas. Os conteúdos são muito abstratos e os professores não sabem ainda como desenvolver um ensino mais dinâmico. Algum deles chegam até a nos culpar pela dinâmica das aulas, acreditando que se a aula não se desenvolve como o planejado é porque não estamos fazendo nossa parte. É ruim porque nós acabamos achando que é verdade mesmo e nos culpamos pela situação (Entrevista).

Das aulas vou levar mais coisas que não devo fazer no mercado de trabalho. Sou de Oeiras, município em que o poder aquisitivo da população é baixo e o acesso à internet é muito ruim. Para você ter ideia, para eu assistir aula preciso colocar um banco na frente de casa, na beira da rua para ter um melhor sinal. Ai, no final das aulas os professores solicitam que os alunos abram as câmaras. É um momento de constrangimento para mim, alguns ainda duvidam e zoam da minha situação. Empatia zero (Entrevista).

Alguma coisa a gente sempre aprende, alguma coisa irei levar para minha atuação profissional. O que mais me preocupa é o que tá ficando pelo caminho, o que tá deixando de ser dito e compreendido. Tem aula que eu não aprendo nada mesmo, fica tudo no plano teórico e abstrato. Saio exausto das aulas, tonto de olhar para o celular e com o ouvido dolorido do fone. O pior de tudo não é isso. Acho que o pior é o adoecimento mental (Entrevista).

Não critico os professores, mas a forma como as aulas são dinamizadas. Parece que são feitas de qualquer jeito, ai vira faz de conta. Não sei sinceramente o que de fato tenho aprendido de novo. Fico péssima, porque por trás do meu processo formativo têm sonhos, pessoas, expectativas (Entrevista).

De modo geral, quando os alunos apontam a dificuldade de aprendizagem e o sofrimento que o ensino remoto tem produzido sobre eles, estão denunciando a precarização e o adoecimento provocado por um sistema de ensino maquiado, que armado do discurso da necessidade de ofertar o ensino remoto emergencial, desconsidera a realidade social, cultural e econômica de milhares de alunos. Estudantes, filhos de trabalhadores e trabalhadoras que tem na educação de seus filhos a esperança de uma vida melhor. Nessa perspectiva, os sentidos produzidos, a partir das falas apresentadas, são demonstrativos de que, os alunos participantes do estudo, o processo de formação profissional no ensino remoto impacta a aprendizagem, bem como a saúde mental. 
Após tudo o que foi até aqui exposto sobre os motivos pessoais produzidos pelos alunos investigados, torna-se possível afirmar o processo de formação profissional em saúde no contexto do ensino remoto, encontra-se desprovido de diálogo, que no decorrer das aulas é instituída a cultura do fingir ensinar e fingir aprender. Que tal processo, tem prejudicado a aprendizagem dos alunos e provocado adoecimento mental na comunidade acadêmica. Faz-se necessário pontuarmos que nos relatos dos alunos além de revelarem novas significações (sentidos pessoais) acerca do processo de formação profissional em saúde no ensino remoto, o que nos leva a pensar que os professores que não receberam nenhum tipo de formação para o desenvolvimento das aulas síncronas, o que faz com que eles apresentem dificuldades em lidar com as novas tecnologias digitais. Portanto, a partir das significações produzidas pelos alunos e das contribuições teóricas dos autores com os quais dialogamos neste estudo, foi possível observarmos que o processo de formação profissional em saúde no ensino remoto, na universidade em que os participantes deste estudo se encontram matriculados, não cumpre sua função social e acaba provocando dor e sofrimento nos alunos.

\section{Considerações finais}

Na busca pela resposta à questão problema deste estudo, a leitura e a análise dos dados produzidos através da entrevista semiestruturada, subsidiada pelos pressupostos teóricos e metodológicos da Pedagogia Freireana especialmente dos pressupostos da categoria diálogo, aproximaram-nos do movimento de produção de sentidos e significados sobre o processo de formação profissional em saúde. No decorrer do processo de investigação, delimitamos uma amostra de 10 (alunos) alunos participantes, sendo 5 (cinco) do curso de licenciatura em Educação Física e 05 do curso de bacharelado em Psicologia e mediante os discursos destes alunos buscamos analisar essas significações.

As falas dos alunos evidenciaram significações, a priori, manifestadas sobre o desenvolvimento das aulas no ensino remoto. Os alunos, enfatizam que o ensino centrado no professor, ancorado na dinâmica da escuta por parte do aluno, na impossibilidade de dizer a palavra, de interação, troca de experiências dificulta o processo de produção de conhecimentos.

De acordo com os alunos investigados, a ausência do diálogo, além de impossibilitar o pronunciamento do mundo através da palavra, institui a cultura do fingir ensinar e do fingir aprender. Para eles, essa situação provoca dor e sofrimento, por se culpabilizarem com relação ao processo de ensino. O que por sua vez, acaba impactando na saúde mental. 
Em síntese, podemos dizer que os sentidos produzidos pelos alunos, dos cursos de Educação Física e Psicologia ao processo de formação profissional em saúde no ensino remoto, os levaram à tomada de consciência quanto ausência do diálogo que dificulta a aprendizagem e impacta na saúde mental.

\section{REFERÊNCIAS}

AGUIAR, W. M. J. (Org.). Sentidos e significados do professor na perspectiva sócio histórica: relatos de pesquisa. São Paulo: Casa do Pedagogo, 2006.

BARBOSA BAPTISTA, A.; VIEIRA FERNANDES, L. Covid-19, análise das estratégias de prevenção, cuidados e complicações sintomáticas. Desafios. Revista Interdisciplinar da Universidade Federal do Tocantins, Tocantins, v. 7, n. esp. 3, p. 38-47, 22 abr. 2020.

CORREIA, M. S.; MIRANDA, M. L. J.; VELERADI, M. A prática da educação física para idosos ancorada na pedagogia freireana: reflexões sobre uma experiência dialógica problematizadora. Movimento, Porto Alegre, v. 17, n. 4, p. 281-297, out./dez. 2011.

FERREIRA, M. J; IRIGOYEN, M, S; CONSOLIM-COLOMBO, F; SARAIVA, J. F. K; DE ANGELIS, K. Physically active lifestyle as an approach to confronting Covid-19. Arquivos Brasileiros de Cardiologia, São Paulo, v. 114, n. 4, p. 601-622, 9 abr. 2020.

FREIRE, P. Ação cultural para a liberdade: e outros escritos. Rio de Janeiro: Paz e Terra, 1976 .

FREIRE, P. Conscientização: teoria e prática da libertação. Uma introdução ao pensamento de Paulo Freire. 3. ed. São Paulo: Moraes, 1980.

FREIRE, P. Educação como prática da liberdade. 3. ed. Rio de Janeiro: Paz e Terra, 1971.

FREIRE, P. Pedagogia da autonomia: saberes necessários à prática educativa. São Paulo: Paz e Terra, 1996.

FREIRE, P. Extensão ou comunicação? 4. ed. Trad. Rosiska Darcy de Oliveira. Rio de Janeiro: Paz e Terra, 1979.

FREIRE, P. Pedagogia da esperança: um encontro com a pedagogia do oprimido. Rio de Janeiro: Paz e Terra, 1997.

FREITAS, A. R. R; NAPIMOGA, M; DONALISIO, M. R. Análise da gravidade da pandemia de Covid-19. Epidemiologia e Serviços de Saúde, Brasília, v. 29, n. 2, 6 abr. 2020.

GASKINS, S.; MILLER, P. J; CORSARO, W. A. Theoretical and methodological perspectives. New directions for child development, San Francisco, v. 58, n. 3, 1992.

LEONTIEV, A. Actividade, consciência, personalidade. Playa, Ciudad de La Habana: Editorial Pueblo y Educación, 1983. 
PITANGA, F. J. G; BECK, C. C; PITANGA, C. P. S. Physical inactivity, obesity and COVID-19: perspectives among multiple pandemics. Bras Ativ Fís Saúde, Florianópolis, v. 25, p. 1-4, 2020.

SILVA, M. R. Bolsonaro e a Covid-19: e daí? "o Brazil tá matando o Brasil”, "do Brasil, SOS ao Brasil”, "chora a nossa pátria, mãe gentil...”. Motrivivência, Florianópolis, v. 32, n. 62, p. $1-19$, jun. 2020.

VIGOTSKI, L. S. A formação social da mente. São Paulo: Martins Fontes, 2007.

WERNECK, H. Se você fingir que ensina, ei finjo que aprendo. Petrópolis. Rio de Janeiro: Vozes, 1992.

\section{Como referenciar este artigo}

CORREIA, M. S; ARAÚJO, N. A; MARQUES, B. G. A ausência do diálogo no processo de formação profissional em saúde no ensino remoto: impactos na aprendizagem e na saúde mental de acadêmicos. Temas em Educ. e Saúde, Araraquara, v. 16, n. 2, p. 648-663, jul./dez. $2020 . \quad$ e-ISSN 2526-3471. ISSN $1517-7947 . \quad$ DOI: https://doi.org/10.26673/tes.v16i2.14403

Submetido em: 20/03/2020

Revisões requeridas: $20 / 06 / 2020$

Aprovado em: 05/08/2020

Publicado em: 27/08/2020 